\title{
Evidence-based Decisioning on the Management of a High Caries Risk Patient-A Case Report
}

\author{
Ahmad H Almehmadi (D) \\ King Abdulaziz University, Faculty of \\ Dentistry, Department of Oral Biology, \\ Jeddah, Saudi Arabia
}

\begin{abstract}
Objective: The evidence-based approach to treatment planning has been at the forefront of clinical dentistry and the use of scientific evidence for clinical decisions has an impact on this case report, where the treatment planning of a high caries risk patient was performed with this approach.

Background: In this case report, management of a 30-year-old female patient with multiple carious lesions in her oral cavity has been discussed, and microbiological tests for caries risk assessment were performed that categorized her in the high caries risk group.

Methods: The management of this patient was formulated by carrying out a systematic search of the literature according to the clinical question. It is the evidence-based dentistry protocol, and the search was carried out in the following databases: PubMed, Embase, Medline, and Google Scholar. The CAMBRA protocol was employed for the management of high caries risk patients.

Results: A total of seven articles that included two randomized clinical trials, one case report, and four retrospective studies were identified for the evidence-based approach of the treatment planning.

Conclusion: The caries management by risk assessment has been advocated in this case report, where the patient was identified in the high caries risk group according to the caries assessment tests (microbiological), and the management was carried out inculcating the CAMBRA protocol.
\end{abstract}

Keywords: caries risk assessment, CAMBRA protocol, high caries risk, caries management, case report

\section{Background}

Dental caries is one of the common diseases that occur in the oral cavity and most of the time the preventive treatment is initiated for the disease without thorough caries risk assessment. It should be noted that the available evidence is limited on the preventive program effectiveness in adults. ${ }^{1,2}$ It is noteworthy that the prevalence of the disease has reduced due to better awareness, improved oral hygiene, and access to regular dental care. Even though there is reduced mean caries prevalence, approximately $15-20 \%$ of the population belong to the high-risk category with about $60 \%$ contributing toward caries development. ${ }^{3}$

Dental caries is a multifactorial disease that necessitates complex interactions between fermentable carbohydrates, acid-producing microorganisms, and host factors. Saliva could be touted as the best tool for caries risk assessment/profiling because all the components of the factors mentioned above can be detected in saliva. ${ }^{4}$ Caries risk profiling and customization of it to suit individual patients
Correspondence: Ahmad H Almehmadi Department of Oral Biology, King Abdulaziz University, Jeddah, Saudi Arabia

Email ahalmehmadi@kau.edu.sa 
should be performed before the initiation of the treatment for the disease. The caries risk profiling can aid the dentists in educating patients to reduce their sugar intake, increase fluoride frequency, or improve oral hygiene to reduce the cariogenic bacterial load in patients. ${ }^{5}$ The need of the hour is the evidence-based approach in making judicious clinical decisions toward the management of complex clinical scenarios such as patients with high caries risk.

Evidence-based dentistry encompasses two components ie, the research component where the scientific evidence related to the case has to be gathered from all available literature sources such as PubMed, Embase, Medline, and Google Scholar. ${ }^{6}$ The clinical component involves the appraisal of the collected data and utilizing it to deliver care to the patient. Among the available levels of evidence, the hierarchy is occupied by the systematic review and meta-analysis in the highest position, followed by randomized clinical trials (RCT), non-RCT, case-control, cohort, case report, and expert opinion. ${ }^{7}$ The crux of evidence-based dentistry relies on its collection of research evidence based on a hierarchical analysis and categorizing them according to its strength and importance to develop the management approach for a patient-centric clinical scenario.

An oral health-care-based approach necessitates clinical decision-making that encompasses an amalgamation of systematic evaluation of available scientific evidence based on the patient's dental and medical condition, clinical proficiency, and patient's preference and requisites for the treatment plan. $^{8}$ This report presents a case with high caries risk that presented with multiple carious lesions and the treatment planning was performed using an evidencebased approach that resulted in the restoration of functional and esthetic rehabilitation.

\section{Case Description}

A 30-year old female patient visited the dental clinic with the chief complaint of wishing to change the bridge on her upper front teeth. The dental history elicited two 3-unit PFM fixed partial denture (FPD) done two years ago in a private clinic. The patient was systemically healthy and did not report any relevant family history. The patient was further probed on the dental history that revealed that the patient underwent multiple restorations on her teeth in a private dental clinic along with the 3-unit PFM FPDs. The patient's diet profile revealed that she consumed high amounts of carbohydrate-rich foods and also sweetened tea. There were no significant findings in the extraoral examination of the patient. The intraoral clinical examination observed bleeding on probing in $85 \%$ of the sites and high levels of plaque were found in all teeth sites when revealed using a disclosing solution (TRACE disclosing solution, YOUNG dental manufacturing, MO, USA). On periodontal probing (UNC 15 probe), there were shallow periodontal pockets $(4 \mathrm{~mm})$ in the mid-buccal sites of \#12, $\# 11, \# 21$, and \#23 and distobuccal sites of \#12, \#22, \#24, and $\# 27$. Also, a slight midline shift toward the right side was observed (Figure 1).

The radiographic examination revealed multiple carious lesions along with apical periodontitis in some teeth (Figure 2). The treatment plan was divided into (1) preventive phase, (2) restorative phase, (3) prosthodontic phase, and (4) maintenance phase. The patient was cooperative and willing to attend dental appointments, but reinforcement for improvement of oral hygiene was required. The patient was assured that her identity including name, address, and medical record will be kept anonymous and informed consent was obtained. Institutional approval to publish the case was obtained.

\section{Evidence-based Methods and Literature Search}

The patient had multiple carious lesions in the oral cavity and caries risk assessment was performed using salivary flow and buffer capacity tests (Figure 3). The levels of Streptococcus mutans and lactobacilli were also evaluated. From the tests, it was observed that the patient belonged to the high caries risk category (Figure 4). The Caries Management by Risk Assessment (CAMBRA) protocol has been utilized for categorization and management of patients with dental caries in children as well as the adult population. ${ }^{9}$ CAMBRA involves the assessment of the etiologic and protective factors along with risk for future disease, thereby formulating an evidence-based treatment plan that is patient-centric. ${ }^{10}$ In this case, the caries risk assessment form (CRA form) was not employed but the microbiological tests were performed to ascertain the risk level of the patient. According to the CAMBRA protocol, the management of high-risk patients involves the following with a recall interval of four months:

1. Nutritional counseling for control of dental disease

2. Over-the-counter fluoride-containing toothpaste- $2 \times /$ day 

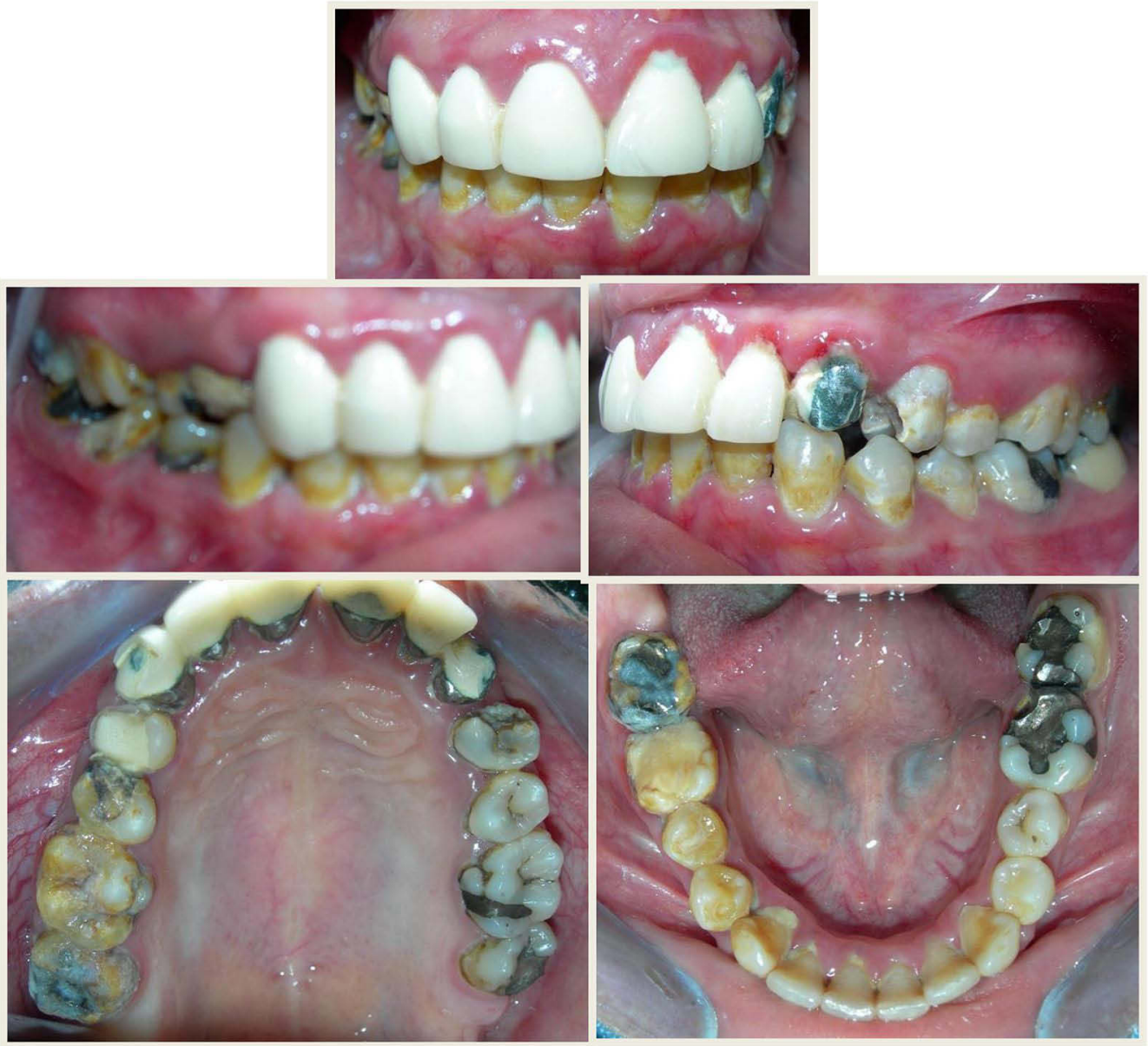

Figure I Preoperative images from different angles showing the ill-fitting crowns and multiple carious lesions.

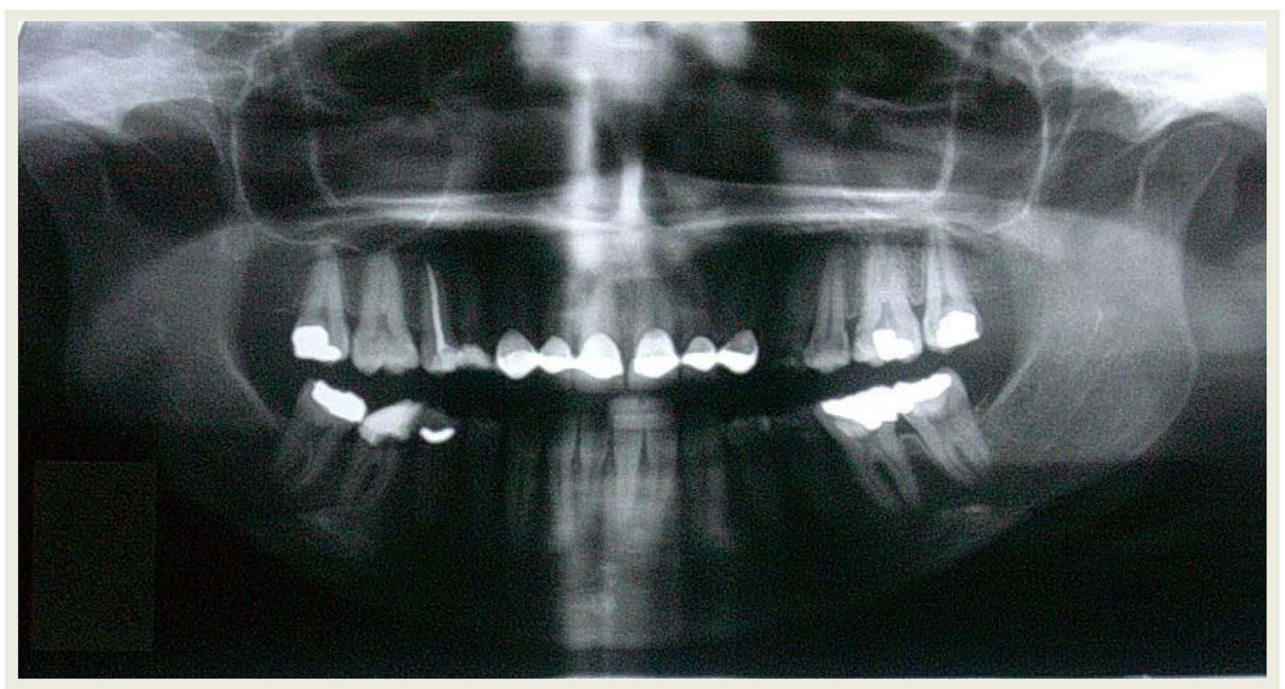

Figure 2 Preoperative panoramic radiograph observing the carious lesions. 


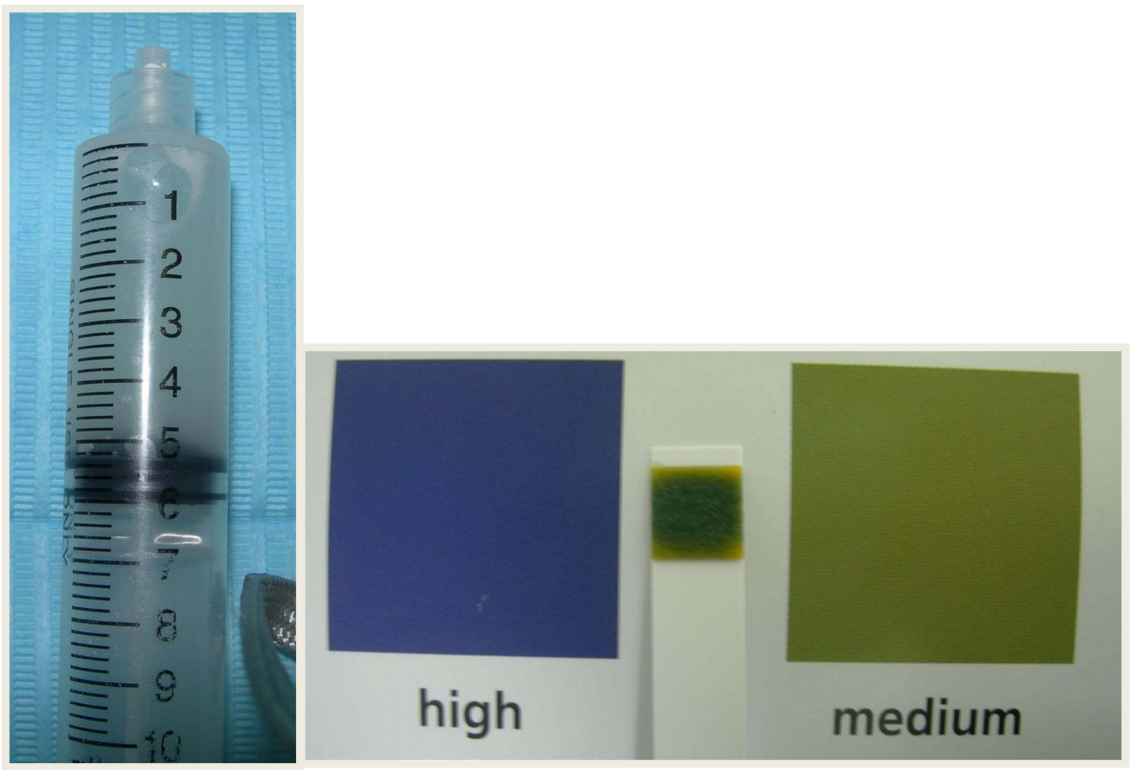

Figure 3 Caries risk assessment using salivary flow and salivary buffer capacity tests.

3. Over-the-counter sodium fluoride rinse daily

4. Over-the-counter xylitol gum or candies-2 gum/ candies, $4 \times /$ day

5. Application of 5\% sodium fluoride varnish (at least twice during the restorative phase of the treatment plan)

6. Chlorhexidine $0.12 \%, 10 \mathrm{~mL}, 1 \times /$ day, one week per month

7. Replace over-the-counter regular fluoride toothpaste with $1.1 \%$ sodium fluoride toothpaste, $2 \times /$ day.

CAMBRA treatment recommendations based on risk assessment level is shown in (Table 1).

The basis was laid from the evidence-based dentistry where the information collected from the patient was translated to the research question based on the PICO format. The PICO format can be elaborated as the patient problem $(\mathrm{P})$, intervention $(\mathrm{I})$, comparison $(\mathrm{C})$, and outcome $(\mathrm{O}) .{ }^{11,12}$ In this report, the PICO format was formulated as for a high caries risk patient $(\mathrm{P})$, the best available treatment plan (I) for the management of the carious lesion $(\mathrm{O})$. There was no comparison for this case. The search of existing literature was performed in databases like Medline, PubMed, Google Scholar, and Embase. The keywords used for this search include "high-caries risk", "caries risk assessment", "risk assessment tests", "salivary flow test", "salivary buffer capacity test", "microbiological test", "caries management”, 'high risk patients' (Figure 5).

The search results yielded seven studies that included two randomized controlled clinical trials, one case report, and four retrospective studies (Table 2). A higher level of evidence in the form of systematic review or meta-analysis could not be procured but a systematic review performed in children regarding the diagnostic accuracy of caries risk assessment methods could assess only the accuracy of levels of $S$. mutans in saliva. It observed that there was a low quality of evidence where the positive likelihood ratio (LR) was lower than 5 and the negative LR was $<0.2$ $\left(\mathrm{LR}+3.32\right.$; LR- 0.64). ${ }^{13}$ Arino et al, in a multicenter study, showed that the caries risk assessment (CART tool) in Japanese adults was a major indicator in the detection of caries development. ${ }^{14}$ A similar result was observed in a retrospective study conducted by Ito et al on the Japanese population. ${ }^{5}$ The clinical significance in this study reinforced that the patient's engagement in a caries preventive program can arrest the initiation and progression of caries. ${ }^{14}$ A randomized controlled clinical trial on anticaries therapies conducted an assessment of salivary microbial counts and fluoride levels and it deciphered that targeted antibacterial and fluorides resulted in favorable alteration in the equilibrium between pathological and defensive factors. ${ }^{15}$ Other epidemiological studies warranted the significance of assessment of caries risk and observed in high-risk individuals that they may not have been targeted with intensive preventive therapy. ${ }^{16-18}$ A case report reviewed the clinical guidelines for the management of caries of differing risks and dealt with the assessment of the high caries risk patient, the treatment plan, and the preventive strategies toward future carious lesions. $^{19}$ 


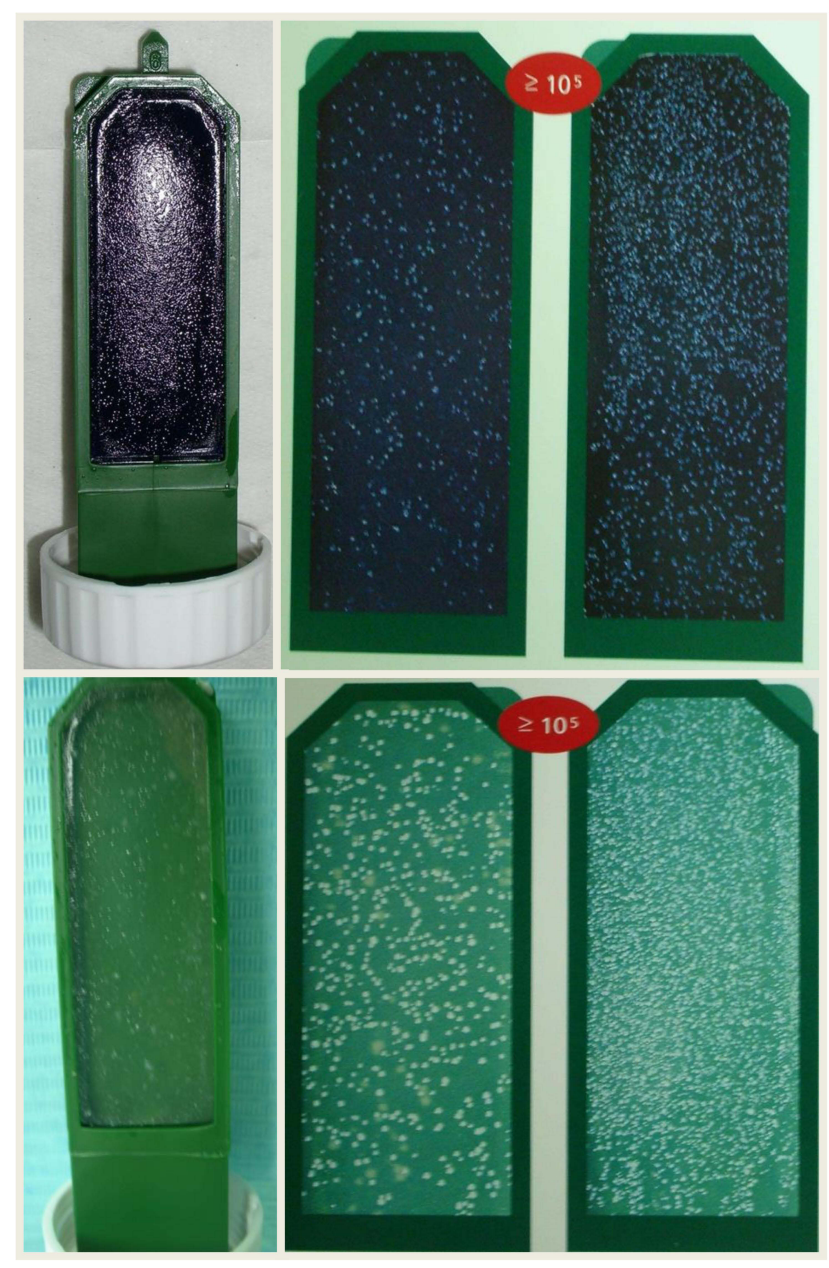

Figure 4 Caries risk assessment evaluating the salivary microbial load of Streptococcus mutans and Lactobacillus spp.

\section{Evidence-based Treatment Plan}

An evidence-based approach was utilized in the development of the treatment plan. Since the patient was assessed to be in the high caries risk category, the CAMBRA clinical guidelines were followed for the management. The nonsurgical periodontal therapy with scaling and root planing was performed. Oral hygiene instructions with diet analysis and modifications were advised to the patient. The patient was motivated and compliant with the instructions. The caries risk assessment based on salivary microbial load was reassessed postpreventive phase and it showed a significant decrease in the colony-forming units. The salivary flow rate was normal in this patient at $5 \mathrm{~mL} / 5$ min. $^{20}$ The caries control was established by excavation and temporization of all active carious lesions.

Phase 2 of the treatment plan was implemented with nonsurgical root canal therapy (NSRCT) performed on the following teeth: \#14, \#13, \#12, \#11, \#21, \#22, \#23, \#24, \#25 (intentional NSRCT), \#36. The following teeth were restored with composite restorations: \#17, \#16, \#14, \#12, \#17, \#26, \#27, \#37, \#36, \#35, \#34, \#45. Phase-III of the treatment plan included placement of post and core in \#16, $\# 13, \# 11$ \#21, \#22, \#23, \#24, \#46, fiber post in \#12 followed by porcelain-fused metal crowns in those teeth along with \#17, \#15, \#14, \#26, \#37, \#36, and \#47.

\section{Follow-up and Prognosis}

The patient had recall visits at 3, 6, and 12 months in one year and the CAMBRA protocol incorporated followup until 24 months. ${ }^{9}$ The oral hygiene maintenance was satisfactory with no biological complications. The timely intervention with caries risk assessment and preventive treatment strategies have eliminated the development of new carious lesions in the patient and the patient was satisfied with the change in her dental health and esthetics. The postoperative images show a successful rehabilitation

Table I CAMBRA Treatment Recommendations Based on Risk Assessment Level

\begin{tabular}{|c|c|c|c|}
\hline Low Risk & Moderate Risk & High Risk & Extremely High Risk \\
\hline $\begin{array}{l}\text { - OTC toothpaste with } \\
\text { fluoride (1000-II00 Ppm } \\
\text { fluoride). } 2 \times \text { daily. }\end{array}$ & $\begin{array}{l}\text { - OTC toothpaste with } \\
\text { fluoride (1000-I I00 ppm } \\
\text { fluoride). } 2 \times \text { daily. } \\
\text { - OTC fluoride rinse } \\
\text { ( } 0.05 \% \text { NaF), daily. } \\
\text { - Xylitol candies or gums } \\
4 \times \text { daily. } \\
\text { - Alternative regimen: } \\
\text { Xylitol candies or gums, } \\
4 \times \text { daily. } \\
\text { Plus: prescription } 5000 \\
\text { Ppm fluoride toothpaste } \\
2 \times \text { daily. }\end{array}$ & $\begin{array}{l}\text { - Xylitol candies or gums } 4 \times \text { daily. } \\
\text { - Prescription } 5000 \text { ppm fluoride } \\
\text { toothpaste } 2 \times \text { daily. } \\
\text { - Chlorhexidine gluconate }(0.12 \%) \text { rinse } \\
\text { I× daily for I week, every month until the } \\
\text { next POE, then reassess. } \\
\text { - Fluoride varnish applied at first visit and } \\
\text { at each POE/CAMBRA recall. }\end{array}$ & $\begin{array}{l}\text { - Xylitol candies or gums } 4 \times \text { daily. } \\
\text { - Prescription } 5000 \text { ppm fluoride } \\
\text { toothpaste } 2 \times \text { daily. } \\
\text { - Chlorhexidine gluconate }(0.12 \%) \text { rinse } \\
\text { I× daily for I week, every month until the } \\
\text { next POE, then reassess. } \\
\text { - Fluoride varnish applied at first visit and } \\
\text { at each POE/CAMBRA recall. } \\
\text { - Baking soda rinse, } 2 \text { tsp in } 8 \text { oz of water, } \\
4 \times \text { to } 6 \times \text { daily. }\end{array}$ \\
\hline
\end{tabular}




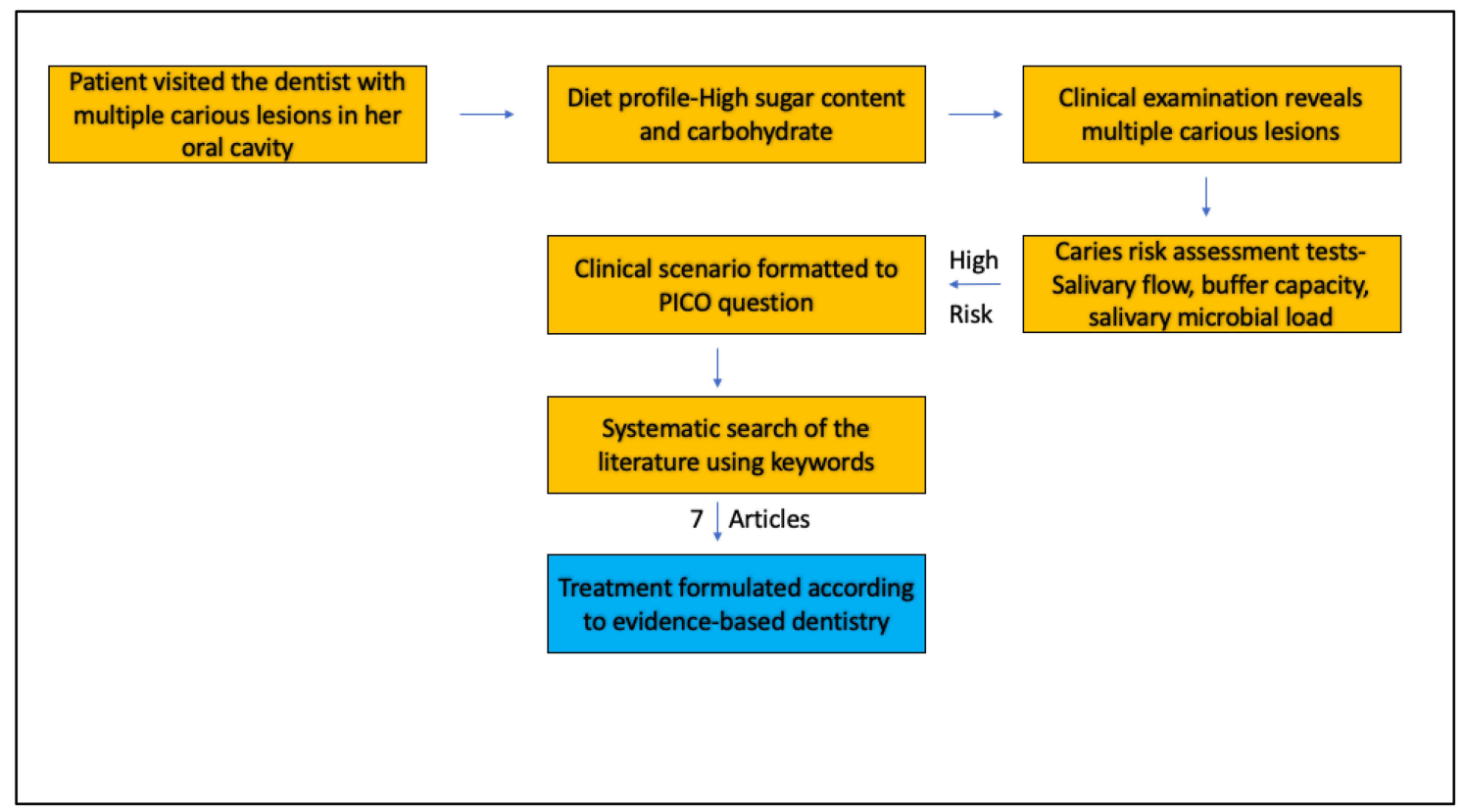

Figure 5 Clinical approach to treatment of high caries risk patient with systematic evidence-based dentistry approach.

in functional and esthetic components for the patient (Figures 6 and 7).

\section{Conclusion}

In this case report, a unique culmination of systematic analysis of scientific literature, dentist's clinical judgment, and patient's needs has resulted in the management of a high caries risk individual. The caries risk assessment tests analyzing the rate of salivary flow, buffer capacity, and bacterial counts identified the individual to belong in the high caries risk category and the CAMBRA protocol was followed for the treatment of caries. The patient's dental management was successful due to the implementation of preventive strategies coupled with accurate diagnosis and treatment planning.

Table 2 List of Included Studies Utilized in the Evidence-based Dentistry Approach in This Report

\begin{tabular}{|c|c|c|}
\hline $\begin{array}{l}\text { Study } \\
\text { No }\end{array}$ & Type of Study & Study Authors, Title, Publication \\
\hline I. & $\begin{array}{l}\text { Randomized clinical } \\
\text { trial }\end{array}$ & $\begin{array}{l}\text { Arino M, Ataru I, Fujiki S, Sugiyama S, Hayashi M. Multicenter study on caries risk assessment in Japanese adult } \\
\text { patients. Journal of Dentistry. } 2015 \mathrm{Oct} ; 43(10): 1223-8 \text {. }\end{array}$ \\
\hline 2. & $\begin{array}{l}\text { Randomized clinical } \\
\text { trial }\end{array}$ & $\begin{array}{l}\text { Featherstone JDB, White JM, Hoover Cl, Rapozo-Hilo M, Weintraub JA, Wilson RS, et al. A randomized } \\
\text { clinical trial of anticaries therapies targeted according to risk assessment (Caries Management by Risk } \\
\text { Assessment). Caries Research. 2012;46(2): I I8-29 }\end{array}$ \\
\hline 3. & $\begin{array}{l}\text { Retrospective } \\
\text { epidemiological }\end{array}$ & $\begin{array}{l}\text { Ito A, Hayashi M, Hamasaki T, Ebisu S. Risk assessment of dental caries by using Classification and Regression } \\
\text { Trees. J Dent. } 20 \text { I I Jun;39(6):457-63. }\end{array}$ \\
\hline 4. & $\begin{array}{l}\text { Retrospective } \\
\text { epidemiological }\end{array}$ & $\begin{array}{l}\text { Chaffee BW, Cheng J, Featherstone JDB. Baseline caries risk assessment as a predictor of caries incidence. } \\
\text { Journal of Dentistry. } 2015 \text { May;43(5):5 I8-24. }\end{array}$ \\
\hline 5. & $\begin{array}{l}\text { Retrospective } \\
\text { epidemiological }\end{array}$ & $\begin{array}{l}\text { Hänsel Petersson G, Ericson E, Twetman S. Preventive care delivered within public dental service after caries } \\
\text { risk assessment of young adults. International Journal of Dental Hygiene. } 2016 \text { Aug;|4(3):2I5-9. }\end{array}$ \\
\hline 6. & $\begin{array}{l}\text { Retrospective } \\
\text { epidemiological }\end{array}$ & $\begin{array}{l}\text { Söderström U, Johansson I, Sunnegårdh-Grönberg K. A retrospective analysis of caries treatment and } \\
\text { development in relation to assessed caries risk in an adult population in Sweden. BMC Oral Health [Internet] }\end{array}$ \\
\hline 7. & Case Report & $\begin{array}{l}\text { Takulla NF, Wolff MS, Schenkel AB. Caries management by risk assessment. NY State Dent J. } 2012 \\
\text { Nov;78(6):4I-5. }\end{array}$ \\
\hline
\end{tabular}




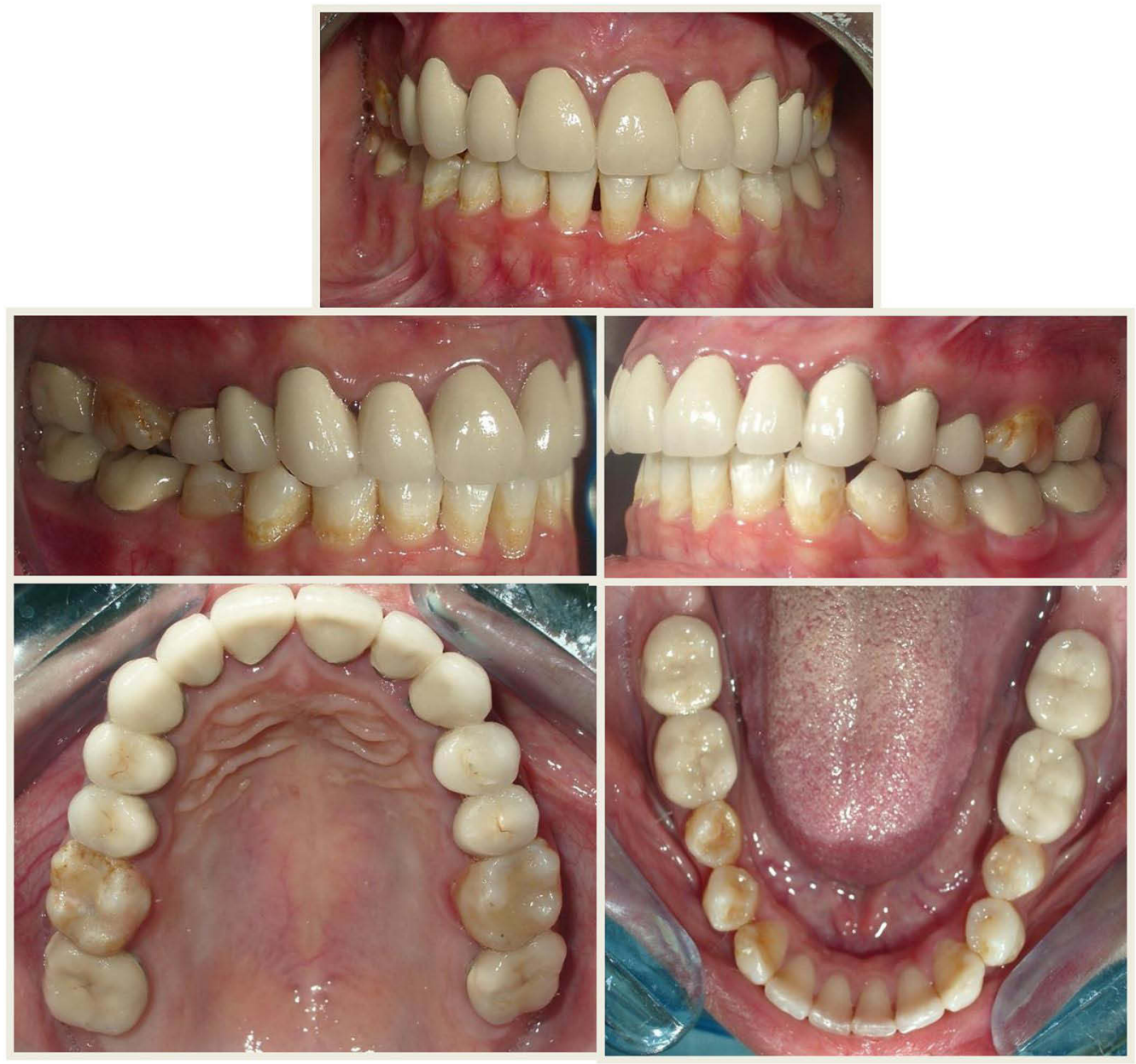

Figure 6 Post-operative images at one-year follow-up showing the functional and esthetic rehabilitation of high caries risk using evidence-based approach.

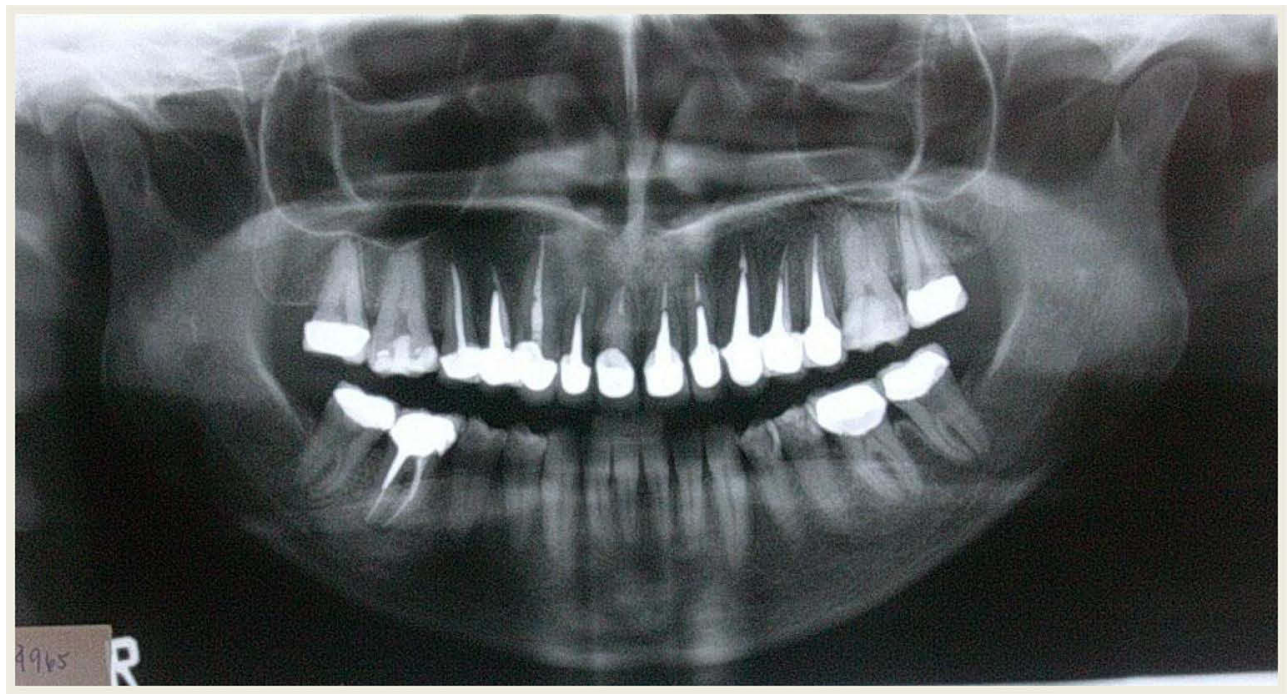

Figure 7 Postoperative panoramic radiograph at one-year follow-up showing the management of high caries risk patient. 


\section{Disclosure}

The author reported no conflicts of interest in this work.

\section{References}

1. Evans R, Pakdaman A, Dennison P, Howe E. The caries management system: an evidence-based preventive strategy for dental practitioners. Application for adults. Aust Dent J. 2008;53(1):83-92. doi:10.1111/ j.1834-7819.2007.00004.x

2. Patel S, Bay RC, Glick M. A systematic review of dental recall intervals and incidence of dental caries. J Am Dent Assoc. 2010;141 (5):527-539. doi:10.14219/jada.archive.2010.0225

3. Burt BA. Prevention policies in the light of the changed distribution of dental caries. Acta Odontol Scand. 1998;56(3):179-186. doi:10.1080/ 000163598422956

4. Guo L, Shi W. Salivary biomarkers for caries risk assessment. J Calif Dent Assoc. 2013;41(2):107.

5. Ito A, Hayashi M, Hamasaki T, Ebisu S. Risk assessment of dental caries by using classification and regression trees. J Dent. 2011;39 (6):457-463. doi:10.1016/j.jdent.2011.04.002

6. Dhar V. Evidence-based dentistry: an overview. Contemp Clin Dent. 2016;7(3):293. doi:10.4103/0976-237X.188539

7. Ismail AI, Bader JD. Evidence-based dentistry in clinical practice. $J$ Am Dent Assoc. 2004;135(1):78-83. doi:10.14219/jada.archive.2004.0024

8. American Dental Association Council on Scientific Affairs. Professionally applied topical fluoride: evidence-based clinical recommendations. $J$ Am Dent Assoc. 2006;137(8):1151-1159. doi:10.14219/jada.archive.2006.0356

9. Young DA, Buchanan PM, Lubman RG, Badway NN. New directions in inter-organizational collaboration in dentistry: the CAMBRA Coalition model. J Dent Educ. 2007;71(5):595-600. doi:10.1002/ j.0022-0337.2007.71.5.tb04316.x
10. Young DA, Featherstone JD, Roth JR. Curing the silent epidemic: caries management in the 21 st century and beyond. $J$ Calif Dent Assoc. 2007;35(10):681-685.

11. Forrest J. Evidence-based decision making: a translational guide for dental professionals. Philadelphia: Lippincott Williams \& Wilkins; 2009.

12. Sackett D, Strauss S, Richardson W, Rosenberg W, Haynes R. Evidence-based medicine: how to practice and teach EBM. Edinburgh: Churchill Livingstone; 2000:3-4.

13. Senneby A, Mejàre I, Sahlin NE, Svensäter G, Rohlin M. Diagnostic accuracy of different caries risk assessment methods. A systematic review. J Dent. 2015;43(12):1385-1393. doi:10.1016/j.jdent.2015.10.011

14. Arino M, Ataru I, Fujiki S, Sugiyama S, Hayashi M. Multicenter study on caries risk assessment in Japanese adult patients. J Dent. 2015;43(10):1223-1228. doi:10.1016/j.jdent.2015.07.010

15. Featherstone JDB, White JM, Hoover CI, et al. A randomized clinical trial of anticaries therapies targeted according to risk assessment (caries management by risk assessment). Caries Res. 2012;46 (2):118-129. doi:10.1159/000337241

16. Chaffee BW, Cheng J, Featherstone JDB. Baseline caries risk assessment as a predictor of caries incidence. J Dent. 2015;43(5):518-524. doi:10.1016/j.jdent.2015.02.013

17. Hänsel Petersson G, Ericson E, Twetman S. Preventive care delivered within Public Dental Service after caries risk assessment of young adults. Int J Dent Hyg. 2016;14(3):215-219. doi:10.1111/idh.12135

18. Söderström U, Johansson I, Sunnegårdh-Grönberg K. A retrospective analysis of caries treatment and development in relation to assessed caries risk in an adult population in Sweden. BMC Oral Health. 2014;14(1):1-11. doi:10.1186/1472-6831-14-126

19. Takulla NF, Wolff MS, Schenkel AB. Caries management by risk assessment. N Y State Dent J. 2012;78(6):41-45.

20. Iorgulescu G. Saliva between normal and pathological. Important Factors in Determining Systemic and Oral Health. J Med Life. 2009;2(3):303.
Journal of Multidisciplinary Healthcare

\section{Publish your work in this journal}

The Journal of Multidisciplinary Healthcare is an international, peerreviewed open-access journal that aims to represent and publish research in healthcare areas delivered by practitioners of different disciplines. This includes studies and reviews conducted by multidisciplinary teams as well as research which evaluates the results or conduct of such teams or healthcare processes in general. The journal

\section{Dovepress}

covers a very wide range of areas and welcomes submissions from practitioners at all levels, from all over the world. The manuscript management system is completely online and includes a very quick and fair peer-review system. Visit http://www.dovepress.com/testimonials. php to read real quotes from published authors. 